\title{
Booster test lifts prospects for new launcher
}

Kourou, French Gulana. The European Space Agency (ESA) is on course to launch its first Ariane 5 rocket in October next year, following the successful third ground test of the rocket's solid fuel booster, carried out last week at the agency's space centre in French Guiana.

The P-230 booster - one of the pair that, when strapped to Ariane 5's central Vulcain cryogenic motor, will provide 92 per cent of thrust at lift-off - is ten times bigger than any rocket previously built by Europe. At 31 metres high and 3 metres in diameter, each booster alone provides more power than the

In 133 seconds, the booster burned 237 tonnes of butadiene, aluminium and ammonium perchlorate propellant. About 230 tonnes of exhaust gases formed a huge white cloud that mushroomed to 11,000 feet above the forest. The firing also pulverized up to 150 tonnes of granite torn from the top 50 centimetres of the rock below the test-bed.

The French space agency CNES, which has responsibility for the tests, admits that the control of pollution from the exhaust is a problem, and restricts tests to 'appropriate' meteorological slots. To prevent the 48.3 tonnes of hydrochloric acid in the cloud from falling on trees, for example, CNES requires 2.5 hours without rain after a test.

Held tightly by an ECU50-million gantry, the booster lifted just 5 centimetres off the ground, sufficient for certain tests to be carried out. First analyses of roughly 600 different measurements suggest that the booster performed as predicted. In particuAriane 4 launcher now in service.

lar, it produced the desired flight thrust profile, including a surge to 540 tonnes in the first 15 seconds.

Development of the solid-fuel boosters accounts for almost a fifth of the ECU6.1 billion cost of the Ariane 5 programme. New industrial ground facilities in Guiana for manufacturing the fuel and assembling the rocket have cost a further ECU910 million; ESA decided that production in situ would be safer and simpler than transporting the boosters from Europe.

CNES will test the

Up to 150 tonnes of granite were pulverized in the test.

booster four more times this year, and Ariane 5 will have its first test flight in October 1995, with a subsequent test in April 1986. ESA will test a small unmanned reentry vehicle attached to the launcher's nose-cone on one of these flights. The first commercial flight of Ariane 5 is scheduled for October 1996

The Ariane 5 programme was approved by ESA members' space ministers at $\mathrm{La}$ Hague in 1987, and is planned to give Europe a more powerful and more reliable launcher that will be 10 per cent cheaper than Ariane 4. France has agreed to pay 46.2 per cent of the costs, with Germany covering 22 per cent and Italy 15 per cent.

On the basis of market research, the agency predicts that satellites weighing be-

\section{FDA claims nicotine levels were manipulated}

Washington. David Kessler, commissioner of the US Food and Drug Administration (FDA), last week presented to a congressional subcommittee "conclusive evidence" that the tobacco industry deliberately manipulates nicotine levels in cigarettes.

Kessler told the health and environment subcommittee of the House Committee on Energy and Commerce that the cigarette manufacturer Brown and Williamson had deliberately developed seeds to produce high-nicotine, low-tar tobacco plants.

Kessler also told the subcommittee, chaired by Henry Waxman (Democrat, California), that at least one other company puts ammonia in cigarettes. The ammonia increases the nicotine levels received by smokers by binding with the salts in tobacco.

"These findings lay to rest any notion that there is no manipulation and control of nicotine undertaken in the tobacco industry," asserted Kessler. The question of whether or not the industry deliberately manipulates nicotine levels is crucial to whether the FDA has the legal right to regulate nicotine as a drug.

The FDA's investigation of the tobacco industry and the slew of congressional hearings during the past few months have been aimed at building support in both Congress and the public for the regulation of cigarettes. Advocates of regulation must win enough votes in Congress to defeat the powerful tobacco lobby.

Two days after Kessler's testimony, Thomas Sandefur, the chief executive of Brown and Williamson, denied the FDA allegations and told the subcommittee he did not believe nicotine to be addictive in the sense that cocaine and heroin are addictive.

The question of addiction will be discussed in August at a meeting of the FDA's drug abuse advisory committee. The relative addictiveness of nicotine compared with other drugs such as cocaine will inevitably arise, as many members of the panel are experts in the treatment of addiction to these illegal drugs.
Helen Gavaghan tween 2.4 and 3.6 tonnes will soon make up three-quarters of the commercial launch market. Arianespace, which now takes half of this market, needs the new launcher to compete with the Russian Proton and Chinese Long March-3 launchers.

Ariane 5 is designed to place two satellites with a mass of $5,900 \mathrm{~kg}$ - or one of $6,800 \mathrm{~kg}$ - into a geostationary transfer orbit $(36,000 \mathrm{~km}), 10$ tonnes into Sun synchronous orbit $(900 \mathrm{~km})$, or 22 tonnes into low Earth orbit $(300 \mathrm{~km})$. ESA is also planning bigger and smaller versions of Ariane 5 .

Designed also to carry the now-abandoned Hermès space shuttle, Ariane 5 should also be sufficiently reliable to give Europe an independent manned flight capacity.

In particular, ESA recently approved a ECU207-million manned programme, including an Apollo-like capsule to be mounted on the nose of Ariane 5. It may also use Ariane 5 to service the international space station, if the US-led project goes ahead.

To achieve its goal of cutting the costs of Ariane 4 by 10 per cent, Ariane 5 will need to make eight flights a year, including five commercial ones. Many think Ariane 5 will make this target, but perhaps not before early next century.

Costs have overrun by 25 per cent, and the Paris-based Euroconsult space consultants say the satellite market may dip between 1996 and 2000. The expected regular Hermès missions will also not now materialize, although space station missions would compensate for this loss.

For its part, Ariane 4 flew two weeks ago for the first time since January, when a failed launch lost satellites worth US\$356 million (see Nature 367, 398; 1994). Arianespace, which has contracts to launch 40 satellites on its order book worth FFr18.7 billion, is speeding up its launch schedule to make up for this five-month delay, required to modify the liquid oxygen/hydrogen turbopump which caused the accident. Declan Butler 